\title{
Oxygen ion uplift and satellite drag effects during the 30 October 2003 daytime superfountain event
}

\author{
B. T. Tsurutani ${ }^{1,2}$, O. P. Verkhoglyadova ${ }^{3,1}$, A. J. Mannucci ${ }^{2}$, T. Araki ${ }^{4}$, A. Sato ${ }^{4}$, T. Tsuda ${ }^{1}$, and K. Yumoto \\ ${ }^{1}$ RISH, Kyoto University, Uji, Japan \\ ${ }^{2}$ Jet Propulsion Laboratory, California Institute of Technology, Pasadena, CA 91109, USA \\ ${ }^{3}$ IGPP, University of California at Riverside, Riverside, CA92521, USA \\ ${ }^{4}$ KUGI, Kyoto University, Japan \\ ${ }^{5}$ SERC, Kyushu University, Fukuoka, Japan
}

Received: 1 March 2007 - Accepted: 6 March 2007 - Published: 29 March 2007

\begin{abstract}
The prompt penetration of interplanetary electric fields (IEFs) to the dayside low-latitude ionosphere during the first $\sim 2 \mathrm{~h}$ of a superstorm is estimated and applied to a modified NRL SAMI2 code for the 30 October 2003 event. In our simulations, the dayside ionospheric $\mathrm{O}^{+}$is convected to higher altitudes $(\sim 600 \mathrm{~km})$ and higher latitudes $\left(\sim \pm 25^{\circ}\right.$ to $\left.30^{\circ}\right)$, forming highly displaced equatorial ionospheric anomaly (EIA) peaks. This feature plus others are consistent with previously published CHAMP electron (TEC) measurements and with the dayside superfountain model. The rapid upward motion of the $\mathrm{O}^{+}$ions causes neutral oxygen $(\mathrm{O})$ uplift due to ion-neutral drag. It is estimated that above $\sim 400 \mathrm{~km}$ altitude the $\mathrm{O}$ densities within the displaced EIAs can be increased substantially over quiet time values. The latter feature will cause increased drag for low-altitude satellites. This newly predicted phenomenon is expected to be typical for superstorm/IEF events.
\end{abstract}

Keywords. Ionosphere (Electric fields and currents; Ionosphere-magnetosphere interactions) - Magnetospheric physics (Electric fields)

\section{Introduction}

The existence of interplanetary electric fields (IEFs) which promptly penetrate to the dayside equatorial region has been recognized for decades (Obayashi, 1967; Nishida, 1968; Kelley et al., 1979). Recently, promptly penetrating electric fields (PPEFs) associated with major IEF events have been discovered to last more than several hours at ionospheric heights (Tsurutani et al., 2004; Maruyama et al., 2004; Mannucci et al., 2005; Sahai et al., 2005; Huang et al., 2005). When these electric fields are intense and are in the dawnto-dusk (eastward if viewed from the Northern Hemisphere)

Correspondence to: B. T. Tsurutani

(bruce.t.tsurutani@jpl.nasa.gov) direction, the fields lead to the $\boldsymbol{E} \times \boldsymbol{B}$ convection of the dayside plasma to higher altitudes and greater (absolute) magnetic latitudes (Tsurutani et al., 2004; Mannucci et al., 2005; Verkhoglyadova et al., 2007). At higher altitudes, the recombination time scales are considerably longer (Tsurutani et al., 2005). Solar photoionization replaces the displaced plasma at lower altitudes, increasing the total electron content (TEC). Similar photochemical and dynamical effects, though much weaker ones, result in developing an additional layer in the equatorial ionosphere during summer (Balan et al., 1998). Later, after the PPEFs subside, the plasma flows down the magnetic lines of force to even greater (absolute) magnetic latitudes. This overall process is called the "dayside superfountain effect" (Tsurutani et al., 2004; Mannucci et al., 2005; Verkhoglyadova et al., 2007). The latter studies were performed using GPS receiver data which measured only ionospheric electrons.

We define a superstorm as an event where the Dst/SYMH index becomes less than $-250 \mathrm{nT}$ (Tsurutani et al., 1992, 2003; Gonzalez et al., 1994). During the magnetic storm of 30 October 2003 the southward excursion of the IMF lasted for more than several hours, resulting in a peak Dst of $\sim-350 \mathrm{nT}$, thus this event was a superstorm. It should be noted that the dayside superfountain effect studied here occurs during the first few hours of a superstorm. Disturbance dynamo effects from auroral zone nightside heating (Blanc and Richmond, 1980; Prölss, 1995; Field et al., 1998; FullerRowell et al., 1998) is also an important storm-time phenomenon. However, the propagation of these auroral zone disturbances to reach the local noon equator takes several hours. Here we are only concerned with the first few hours of the PPEF/magnetic storm event. The combined effect of a PPEF and a disturbance dynamo is an interesting topic which deserves a separate study.

The 30 October 2003 (Halloween) positive ionospheric storm was investigated by Mannucci et al. (2005) using both CHAMP and ground GPS receiver data. The CHAMP 
TEC data showed a poleward motion of the EIAs (Namba and Maeda, 1939) to latitudes as high as $\pm 30^{\circ}$ magnetic latitude during the IEF event. The TEC intensification at these latitudes became greater than $\sim 300$ TECU (or $\sim 600 \%$ of the normal quiet time values), where a TECU is $10^{16}$ electrons $/ \mathrm{m}^{2}$ column density. Ground-based TEC values increased by more than $\sim 100$ TECU (or $\sim 200 \%$ ) averaged over a broad $\pm 40^{\circ}$ MLAT region of the ionosphere from 14:00 to 16:00 LT (Mannucci et al., 2005). Tsurutani et al. (2006) have noted high levels of $\mathrm{O}^{+}$ions at DMSP altitudes $(\sim 840 \mathrm{~km})$ during this PPEF event. The in situ densities reached $9 \times 10^{5} \mathrm{~cm}^{-3}$ compared to a quiet-time peak value of $1.5 \times 10^{5} \mathrm{~cm}^{-3}$.

This present effort will focus on modeling the dayside ionospheric $\mathrm{O}^{+}$ion behavior during this magnetic superstorm/IEF event. An estimate of the PPEF will be made from satellite magnetometer data and this will serve as the input to a modified version of the NRL SAMI2 ionospheric code (Huba et al., 2000). The $\mathrm{O}^{+}$ions will be traced during the application of the PPEF and then after the PPEF is terminated. Using the model results, ion-neutral drag will be estimated. It is found that substantial neutral density enhancements at high altitudes potentially occur as part of this superfountain process.

\section{Results}

\subsection{Estimation of Ionospheric Electric Field}

The Kyoto University ionospheric model (http://swdcwww. kugi.kyoto-u.ac.jp/ionocond/index.html) for the particular event is used to obtain ionospheric conductivity values. For 30 October 2003 at an altitude of $105 \mathrm{~km}$ at the equator at noon, the Pederson conductivity $\sigma_{P}$ of $5 \times 10^{-5} \mathrm{~S} / \mathrm{m}$ and a Hall conductivity $\sigma_{H}$ of $9.8 \times 10^{-4} \mathrm{~S} / \mathrm{m}$ are estimated. Thus the Cowling conductivity, $\sigma_{H}^{2} / \sigma_{P}$, is $1.9 \times 10^{-2} \mathrm{~S} / \mathrm{m}$. The CHAMP magnetic field perturbation (at an altitude of $\sim 420 \mathrm{~km}$ ) due to the EEJ intensification during the 30 October 2003 PPEF event was $\sim 90 \mathrm{nT}$. The technique used is discussed in the paper by McCreadie and Iyemori (2006). Assuming a ground reflectance of $\sim 11 \%$ (Richmond, 1995; A. Richmond, personal communication, 2006) and an infinite line current $\mathrm{I}\left(\mathrm{I}=\Delta \mathrm{B} 2 \pi \mathrm{r} / \mu_{O}\right)$ centered at $\sim 105 \mathrm{~km}$ altitude, an electric field value of approximately $4 \mathrm{mV} / \mathrm{m}$ is obtained. In the above expression, $\triangle \mathrm{B}$ is the magnetic perturbation detected at CHAMP, $r$ is the distance of the line current to the observation point, and $\mu_{O}$ is $4 \pi \times 10^{-7}$ in mks units.

\subsection{Modified SAMI2 model}

To understand quantitatively the effects of a storm-time eastward PPEF in the ionosphere and specifically the dynamics of $\mathrm{O}^{+}$ions, we perform numerical simulations based on a modified SAMI2 model. The SAMI2 model is a low-latitude ionospheric code which uses empirical models of the neutral atmosphere (NRLM-SISE00 and HWM) and describes the dynamics and chemical evolution of seven ion species (Huba et al., 2000). SAMI2 traces electrons and ions along the Earth's dipole magnetic field lines, taking into account photoionization of neutrals, ionization, recombination and chemical reactions. Drift of magnetic flux tubes defines the ionospheric plasma transport in a direction perpendicular to the magnetic field. The $\boldsymbol{E} \times \boldsymbol{B}$ vertical drift is caused by the eastward polarization electric field (Kelley, 1989) superimposed on the Earth's background magnetic field. The stormtime drift can be introduced into SAMI2 by using two superposed electric fields. We will use the SAMI2 "sine" model for calculating the background or undisturbed ion density altitude profiles (Huba et al., 2000). The vertical drift velocity is specified to be proportional to $\sin ([\mathrm{t}-7] / 24)$, where $\mathrm{t}$ is the local time in hours. It was demonstrated by Huba et al. (2002) that the $\mathrm{O}^{+}$density distribution with the sine electric field is in good agreement with observed $\mathrm{O}^{+}$altitude profiles for geomagnetic quiet times. Polarization electric field amplitude of $0.53 \mathrm{mV} / \mathrm{m}$ (corresponding to an upward velocity of $15 \mathrm{~m} / \mathrm{s}$ ) will be assumed in the present work.

We impose a second electric field to represent the stormtime PPEF. A square wave PPEF of $4 \mathrm{mV} / \mathrm{m}$ magnitude is added to the "sine" model for $2 \mathrm{~h}$. This electric field intensity is assumed to be the same in both the E-region and the F-region of the ionosphere (Mozer, 1970; Anderson et al., 2002; D. Anderson, personal communication, 2006). This electric field is equivalent to an upward velocity of $\sim 114 \mathrm{~m} / \mathrm{s}$. Since the magnetic field is nearly constant in magnitude close to the Earth, we neglect the corresponding small differential changes of the drift velocity. Although in actuality it is the plasma velocity that is inputted into the model, we will hereafter describe this as an electric field input to focus on the physics of the real situation. The simulations are performed for the region from $-35^{\circ}$ to $+35^{\circ}$ geographic latitude and from $85 \mathrm{~km}$ to $3000 \mathrm{~km}$ in altitude.

Figure 1a shows the results of the first step in the simulation. The sine (background) model electric field is an input to SAMI2. The resultant profile of $\mathrm{O}^{+}$ions at 02:00 p.m. local time is shown in the figure. The normal EIA peaks are detected at $\sim+10^{\circ}$ latitude at $340 \mathrm{~km}$ and $-22^{\circ}$ latitude at $\sim 400 \mathrm{~km}$ altitude, respectively. The asymmetry of the peaks may be caused by neutral winds which are included in the modeling, and also by offsets between geographic and geomagnetic coordinates (only geographic coordinates are shown here). Next a step-like electric field is superimposed on the "sine" variations from noon to 02:00 p.m. local time (LT) at all altitudes. The result in Fig. 1b shows a clear uplift of the density maxima. The ion density peaks are now located at $\sim 23^{\circ}$ latitude and $\sim 620 \mathrm{~km}$ altitude in the north and $-33^{\circ}$ latitude and $\sim 600 \mathrm{~km}$ altitude in the Southern Hemisphere. The magnitude of the peak density has also increased from $\sim 4 \times 10^{6} \mathrm{~cm}^{-3}$ to $\sim 5.6 \times 10^{6} \mathrm{~cm}^{-3}$ in the north. Note that the uplift causes a relative density increase at all altitudes 

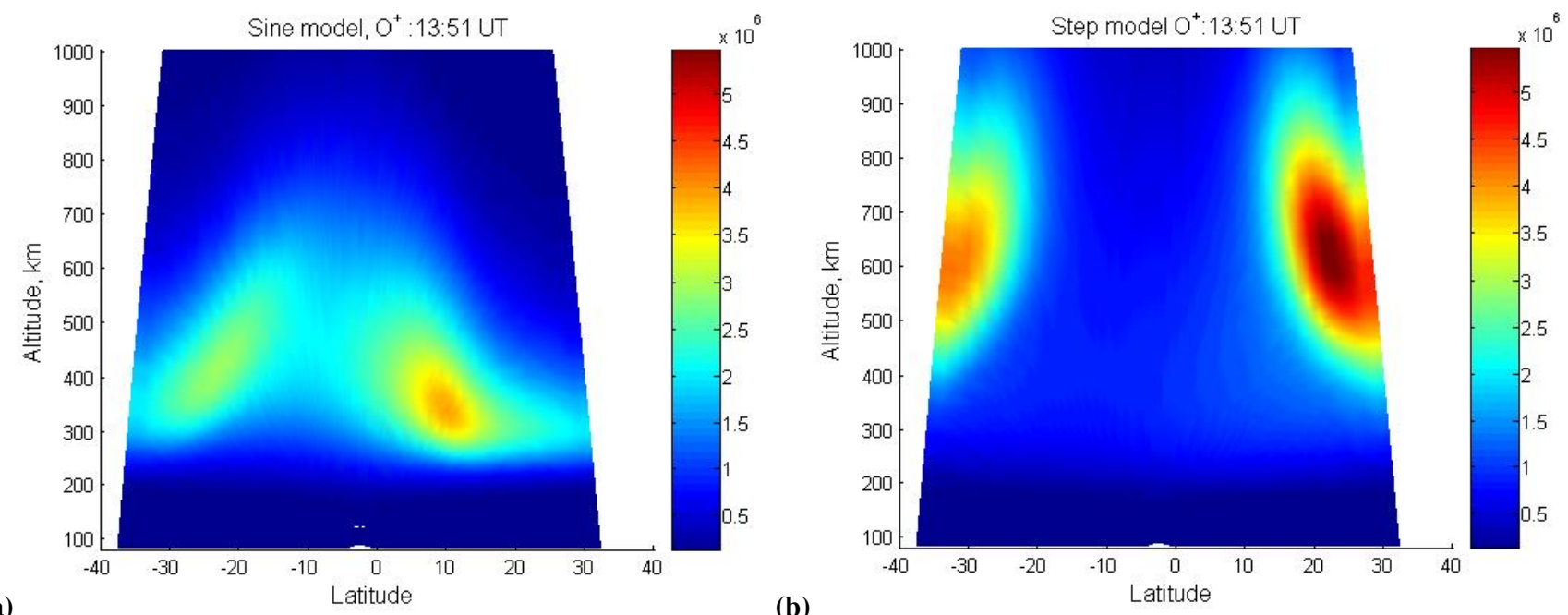

(a)

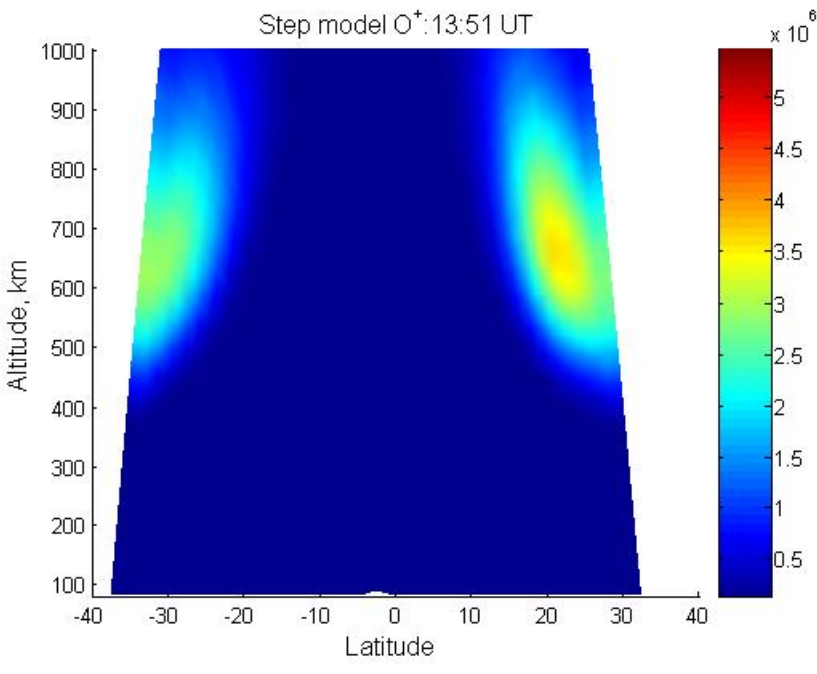

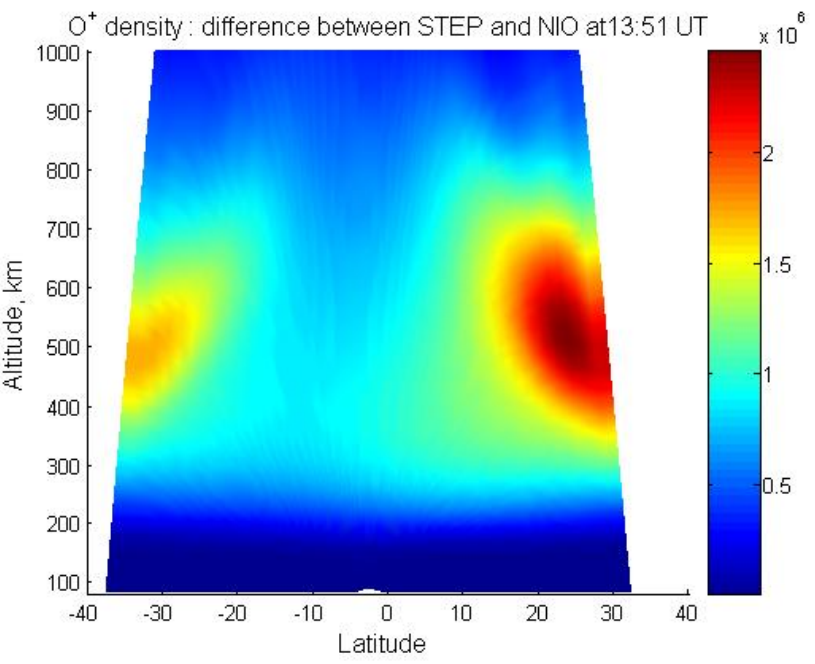

Fig. 1. Modeling of $\mathrm{O}^{+}$ion uplift during strong IEF events/magnetic storms. The color insets on the right of each panel show the local ion density in $\mathrm{cm}^{-3}$. The following models of $\boldsymbol{E} \times \boldsymbol{B}$ drift were used: a "sine" wave background model (a), a PPEF step model (b), and the step model without solar photoionization (c). All density profiles are shown for $\sim$ 02:00 p.m. local time. Differences in the ion density between the step model with and without ionization is also shown (d). Notice the maximum difference occurs at $\sim 500 \mathrm{~km}$ and for $\sim 25^{\circ}$ latitude.

above $350 \mathrm{~km}$ to almost $900 \mathrm{~km}$ in the latitude range of $20^{\circ}$ to $35^{\circ}$ geographical latitude. This result is generally consistent with the observed uplift of $\mathrm{O}^{+}$at DMSP satellite altitudes $(\sim 840 \mathrm{~km})$ (Tsurutani et al., 2006). However detailed modeling will be necessary to match the DMSP ion temporal variations and local time ( 09:30 a.m.) dependence of the observations.

What is the role of solar photoionization in this process? To study this, the step model for a case without photoionization is run. The sun is "turned off" by artificially stopping the photoionization process from noon until 02:00 p.m. The ionospheric density profile is shown in Fig. 1c. The $\mathrm{O}^{+}$profile is very similar to the previous case but with a slightly higher maximum located at $\sim 670 \mathrm{~km}$ altitude. The maximum has a value of $\sim 3.6 \times 10^{6} \mathrm{~cm}^{-3}$, which is only $\sim 60 \%$ of the value when ionization was present. To better visual- ize this effect, the quantitative differences between the two cases was plotted, i.e., a step electric field with and without the ionization. The results are shown in Fig. 1d. This panel indicates that at least three factors contribute to the uplifted maximum of $\mathrm{O}^{+}$ions. First, the uplift itself is due to $\boldsymbol{E} \times \boldsymbol{B}$ convection caused by the storm-time electric field penetrating into the ionosphere. The second factor is the creation of a "new" ionosphere at lower altitudes in place of the uplifted ions. This is caused by solar photoionization. The third factor is gravity. These factors combined explain why the maximum $\mathrm{O}^{+}$density in the presence of photoionization occurs at a lower altitude than the corresponding maximum without ionization. The largest difference in the density lies between 400 and $600 \mathrm{~km}$ (see Fig. 1d), i.e., lower than the maximum in Fig. $1 b$. 


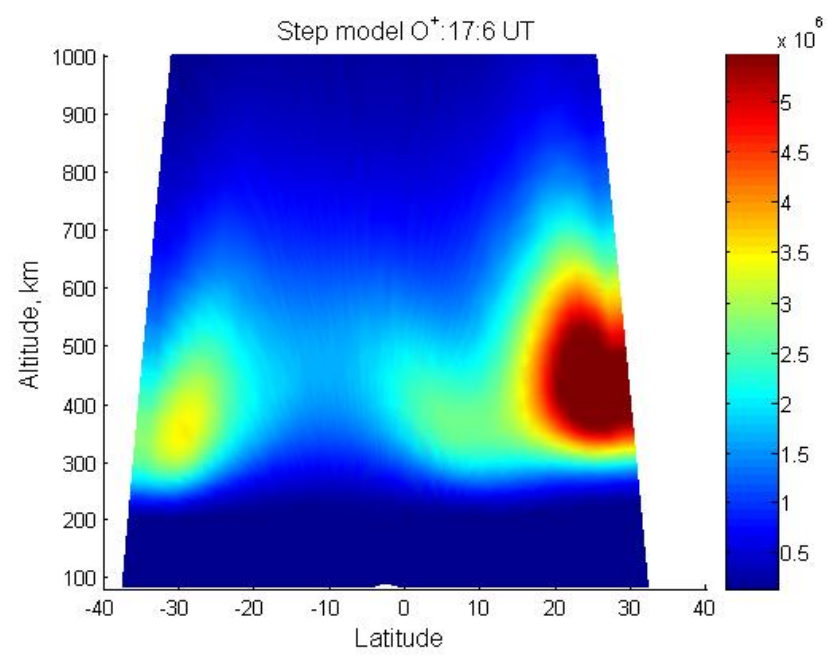

Fig. 2. Modeling of $\mathrm{O}^{+}$ion gravitational downdraft at $3 \mathrm{~h}$ after the PPEF has been turned off. The color insets on the right of each panel show the local ion density in $\mathrm{cm}^{-3}$. Notice the maximum density has shifted from $\sim 620 \mathrm{~km}$ to $\sim 430 \mathrm{~km}$ in altitude and to higher latitudes.

Figure 2 shows the $\mathrm{O}^{+}$ion density distribution for a PPEF step model (corresponding to Fig. 1b), $3 \mathrm{~h}$ after the electric field has been turned off. It can be noted that the $\mathrm{O}^{+}$ions have descended in altitude. The two peaks are located at $\sim 430 \mathrm{~km}$ and $\sim 480 \mathrm{~km}$ and $+25^{\circ}$ and $-33^{\circ}$ in latitude, respectively. The magnitude of the peak density has increased from $\sim 5.6 \times 10^{6} \mathrm{~cm}^{-3}$ to $\sim 7.0 \times 10^{6} \mathrm{~cm}^{-3}$. An explanation is that the plasma has gravitationally fallen down along the Earth's magnetic field lines and, consequently, moved to higher latitudes. The higher density can be explained by a concentration of $\mathrm{O}^{+}$ions at the bottom of the converging magnetic flux tubes, or a magnetic "focusing" effect.

\subsection{Estimation of ion-neutral drag}

With $\mathrm{O}^{+}$ions being rapidly uplifted, one can expect corresponding uplift of neutrals by drag forces. A simplified ion-neutral momentum exchange (Baron and Wand, 1983; Kosch et al., 2001) is given by: $\frac{\partial U}{\partial t}=\frac{1}{\tau_{i n}}\left(V_{d}-U\right)$ and the ion-neutral coupling time constant $\tau_{i n}$ (Killeen et al., 1984) given by:

$\tau_{\text {in }}=\frac{n_{0}}{n_{i}} \frac{1}{v_{i n}}$

In the above, $U$ is the vertical velocity of the oxygen atoms due to the ion-neutral drag, $V_{d}$ is the vertical $\boldsymbol{E} \times \boldsymbol{B}$ drift of $\mathrm{O}^{+}$ions due to the storm-time PPEF, $\mathrm{n}_{0}$ and $\mathrm{n}_{i}$ are the neutral oxygen and ion densities, and $v_{i n}$ is the ion-neutral collision frequency.

We calculate ion-neutral drag for a representative altitude of $\sim 340 \mathrm{~km}$ at $\sim 10^{\circ}$ latitude starting at noon. This location has been chosen because it is near the
EIA peak location where this effect is approximately a maximum. We estimate the oxygen ion-neutral collision frequency using formula by Bailey and Balan (1996): $v_{i n} \approx 4.45 \times 10^{-11} \cdot n_{0} \cdot T^{1 / 2} \cdot\left(1.04-0.067 \log _{10} T\right)^{2} . T$ is the average of the neutral and ion oxygen temperatures. Using $\mathrm{O}^{+}$and $\mathrm{O}$ temperatures of $\sim 10^{3} \mathrm{~K}$, oxygen ion and neutral densities of $\sim 3.5 \times 10^{6} \mathrm{~cm}^{-3}$ and $1.1 \times 10^{9} \mathrm{~cm}^{-3}$ at noon, one gets $v_{i n} \approx 10^{-9} \cdot n_{0} \approx 1.1 \mathrm{~s}^{-1}$ or $\tau_{i n} \sim 5 \mathrm{~min}$ according to Eq. (1).

The first-order expectation of neutral density increases can be roughly estimated in a simple way. Assuming that the upward momentum of ions is transferred to upward neutral oxygen momentum by ion-neutral collisions, the neutrals at $\sim 340 \mathrm{~km}$ altitude and $10^{\circ}$ latitude will be displaced to $\sim 370 \mathrm{~km}$ after $2 \mathrm{~h}$ of $\sim 4 \mathrm{mV} / \mathrm{m}$ PPEFs. This will result in up to a $60 \%$ neutral density increase at the latter altitude. This physical process will have greater resultant effects at higher altitudes due to the lower neutral background densities. At $\sim 600 \mathrm{~km}$ altitude, the density increase can be as high as a factor of 5 to 10 .

For a more accurate estimation, an ion-neutral model taking into account gravity effects and heating and expansion during the uplift process is needed. Additionally the uplifted neutrals will eventually fall down, possibly leading to atmospheric/ionospheric heating. Determination of the magnitude of these effects is beyond the scope of the present paper. The dayside superfountain process is a nonlinear one and an ionneutral convective code is needed to be developed and implemented to obtain better estimates. This effort is currently in progress.

\section{Conclusions}

A $4 \mathrm{mV} / \mathrm{m}$ eastward PPEF during the 30 October 2003 superstorm was calculated based on CHAMP magnetometer data, the Kyoto University ionospheric model and a simplified model of the EEJ. The dayside superfountain event was modeled using a modified SAMI2 ionospheric model with the estimated PPEF as an input. The simulation results show uplift of the EIA oxygen ions to higher latitudes and altitudes, creation of a "new" ionosphere at lower altitudes in the place of the uplifted ions, and a subsequent gravitational "downdraft" process after the electric field has been terminated. An accompanying effect of the rapid oxygen ion uplift is the increase of neutral oxygen densities at ionospheric altitudes caused by ion-neutral drag. It is argued that the neutral atmosphere where the EIA ion density peaks exist will be moved upward and poleward by ion-neutral drag. Other areas of the near-equatorial ionosphere should also have neutral $\mathrm{O}$ increases caused by the same mechanism, but to a lesser degree. For a $4 \mathrm{mV} / \mathrm{m}$ electric field lasting for $2 \mathrm{~h}$, the neutral density increase at $600 \mathrm{~km}$ altitude should be a factor of up to an order of magnitude greater than the quiet time values. A more accurate ion-neutral coupling model is currently 
being developed. This superfountain effect should be easily measurable. Enhanced satellite deceleration should occur as satellites cross the displaced and uplifted EIAs at middle latitudes (at $\sim 25^{\circ}$ to $30^{\circ}$ latitudes). Deceleration should occur at other latitudes as well, but to a lesser extent.

Acknowledgements. Portions of this work were performed at the Jet Propulsion Laboratory, California Institute of Technology under contract with NASA. Two of us (B. T. Tsurutani and O. P. Verkhoglyadova) wish to thank RISH, Kyoto University for hosting us during our visit and the writing of this paper. This work uses the SAMI2 ionosphere model written and developed by the Naval Research Laboratory. We wish to thank J. Huba for guidance to some intricacies of the SAMI 2 code and R. Heelis for pointing out some important references.

Topical Editor M. Pinnock thanks one referee for her/his help in evaluating this paper.

\section{References}

Anderson, D., Anghel, A., Yumoto, K., Ishitsuka, M., and Kudeki, E.: Estimating daytime vertical $\mathrm{ExB}$ drift velocities in the equatorial F-region using ground-based magnetometer observations, Geophys. Res. Lett., 29, 12, 37-1, doi:10.1029/2001GL014562, 2002.

Bailey, G. J. and Balan, N.: A low-latitude ionosphereplasmasphere model, in: STEP: Handbook of Ionospheric Models, edited by: Schunk, R. W., p. 173, Utah State Univ., Logan, Utah, 1996.

Balan, N., Batista, I. S., Abdu, M. A., MacDougall, J., and Bailey, G. J.: Physical mechanism and statistics of occurrence of an additional layer in the equatorial ionosphere, J. Geophys. Res., 103, 29 169-29 181, 1998.

Baron, M. J. and Wand, R. H.: F region ion temperature enhancements resulting from Joule heating, J. Geophys. Res., 88, 41144118, 1983.

Blanc, M. and Richmond, A. D.: The ionospheric disturbance dynamo, J. Geophys. Res., 85, 1669-1686, 1980.

Field, P. R., Rishbeth, H. , Moffett, R. J., Idenden, D. W., FullerRowell, T. J., Millward, G. H., and Aylward, A. D.: Modelling composition changes in F-layer storms, J. Atmos. Solar-Terr. Phys., 60, 523-543, 1998.

Fuller-Rowell, T. J., Codrescu, M. V., Araujo-Pradere, E., and Kutiev, I.: Progress in developing a storm-time ionospheric correction model, Adv. Space Res., 22, 821-827, 1998.

Gonzalez, W. D., Joselyn, J. A., Kamide, Y., Kroehl, H. W., Rostoker, G., Tsurutani, B. T., and Vasyliunas, V. M.: What is a geomagnetic storm?, J. Geophys. Res., 99, 5771-5792, 1994.

Huang, C.-S., Foster, J. C., Goncharenko, L. P., Erickson, P. J., Rideout, W., and Coster, A. J.: A strong positive phase of ionospheric storms observed by the Millstone Hill incoherent scatter radar and global GPS network, J. Geophys. Res., 110, A6, doi:0.1029/2004JA010865, 2005.

Huba, J. D., Joyce, G., and Fedder, J. A.: Sami2 is another model of the ionosphere (SAMI2): a new low-latitude ionosphere model, J. Geophys. Res., 105(A10), 23 035-23 054, 2000.

Huba, J. D., Dymond, K. F., Joyce, G., Budzien, S. A., Thonnard, S. E., Fedder, J. A., and McCoy, R. P.: Comparison of $\mathrm{O}^{+}$density from ARGOS LORAAS data analysis and SAMI2 model results,
Geophys. Res. Lett., 29, 7, 6-1, doi:10.1029/2001GL013089, 2002.

Kelley, M. C.: The Earth's Ionosphere: Plasma Physics and Electrodynamics, Elsevier, New York, 1989.

Kelley, M. C., Fejer, B. G., and Gonzales, C. A.: An explanation for anomalous equatorial ionospheric electric field associated with a northward turning of the interplanetary magnetic field, Geophys. Res. Lett., 6(4), 301-304, 1979.

Killeen, T. L., Hays, P. B., Carignan, G. R., Heelis, R. A, Hanson, W. B., Spencer, N. W., and Brace, L. H.: Ion-neutral coupling in the high-latitude $\mathrm{F}$ region: Evaluation of ion heating terms from Dynamics Explorer 2, J. Geophys. Res., 89, 7495-7508, 1984.

Kosch, M. J., Cierpka, K., Rietveld, M. T., Hagfors, T., and Schlegel, K.: High-latitute geround-based observations of the thermospheric ion-drag constant, Geophys. Res. Lett., 28(7), 1395-1398, 2001.

Mannucci, A. J., Tsurutani, B. T., Iijima, B. A., Komjathy, A., Saito, A., Gonzalez, W. D., Guarnieri, F. L., Kozyra, J. U., and Skoug, R.: Dayside global ionospheric response to the major interplanetary events of October 29-30, 2003 "Halloween Storms", Geophys. Res. Lett., 32, L12S02, doi:10.1029/2004GL021467, 2005.

Maruyama, T., Ma, G., and Nakamura, M.: Signature of TEC storm on 6 November 2001 derived from dense GPS receiver network and ionosonde chain over Japan, J. Geophys. Res., 109, A10, doi:10.1029/2004JA010451, 2004.

McCreadie, H. and Iyemori, T.: Equatorial electrojet as a diagnostic tool of geomagnetic field models, Earth Planets Space, 58, 885893, 2006.

Mozer, F. S.: Electric field mapping in the ionosphere at the equatorial plane, Planet. Space Sci., 18, 259-263, 1970.

Namba, S. and Maeda, K.-I.: Radio Wave Propagation, 86 pp., Corona, Tokyo, 1939.

Nishida, A.: Coherence of geomagnetic DP2 fluctuations with interplanetary magnetic variations, J. Geophys. Res., 73, 5549-5559, 1968.

Obayashi, T.: The interaction of solar plasma with geomagnetic field, disturbed condition, in: Solar Terrestrial Physics, 107, edited by: King, J. W. and Newman, W. S., Acad. Press., London, 1967.

Prölss, G. W.: Common origin of positive ionospheric storms at middle latitudes and the geomagnetic activity effect at low latitudes, J. Geophys. Res., 98, 5981-5991, 1993.

Richmond, A. D.: Modeling equatorial electric fields, J. Atmos. Solar Terr. Phys., 57(10), 1103-1115, 1995.

Sahai, Y., Fagundes, P. R., Becker-Guedes, F., Bolzan, M. J. A., Abalde, J. R., Pillat, V. G., de Jesus, R., Lima, W. L. C., Crowley, G., Shiokawa, K., MacDougall, J. W., Lan, H. T., Igarashi, K., and Bittencourt, J. A.: Effects of the major geomagnetic storms of October 2003 on the equatorial and low-latitude F region in two longitudinal sectors, J. Geophys. Res., 110, A12, doi:10.1029/2004JA010999, 2005.

Tsurutani, B. T., Gonzalez, W. D., Tang, F., and Lee, Y. T.: Great magnetic storms, Geophys. Res. Lett., 19, 73-76, 1992.

Tsurutani, B. T., Gonzalez, W. D., Lakhina, G. S., and Alex, S.: The extreme magnetic storm of 1-2 September 1859, J. Geophys. Res., 108, A7, SSH 1-1, doi:10.1029/2002JA009504, 2003.

Tsurutani, B. T., Mannucci, A., Iijima, B., Abdu, M. A., Sobral, J. H. A., Gonzalez, W. D., Guarnieri, F. L., Tsuda, T., Saito, A., Yu- 
moto, K., Fejer, B., Fuller-Rowell, T. J., Kozyra, J., Foster, J. C., Coster, A. J., and Vasyliunas, V. M.: Global dayside ionospheric uplift and enhancement associated with interplanetary electric fields, J. Geophys. Res., A08302, doi:10.1029/2003JA010342, 2004.

Tsurutani, B. T., Judge, D. L., Guarnieri, F. L., Gangopadhyay, P., Jones, A. R., Nuttall, J., Zambon, G. A., Didkovsky, L., Mannucci, A. J., Iijima, B., Meier, R. R., Immel, T. J., Woods, T. N., Prasad, S., Floyd, L., Huba, J., Solomon, S. C., Straus, P., and Viereck, R.: The October 28, 2003 extreme EUV solar flare and resultant extreme ionospheric effects: Comparison to other Halloween events and the Bastille Day event, Geophys. Res. Lett., 32, 3, doi:10.1029/2004GL021475, 2005.
Tsurutani, B. T., Saito, A., Verkhoglyadova, O. P., Mannucci, A. J., Abdu, M. A., Araki, T., Gonzalez, W. D., Iijima, B. A., Lakhina, G. S., McCreadie, H., Sobral, J. H. A., Tsuda, T., Yumoto, K., and Vasyliunas, V. M.: The dayside ionospheric "Superfountain" (DIS), plasmas transport and other consequences, in: Solar Influence on the Heliosphere and Earth's Environment: Recent Progress and Prospects, Proc. ILWS Workshop, Goa, India, 1924 February, edited by: Gopalswamy, N. and Bhattacharyya, A., Quest Publications, 384-387, 2006.

Verkhoglyadova, O. P., Tsurutani, B. T., and Mannucci, A. J.: Modeling of time development of TEC variations during a superstorm event, edited by: Bhardwaj, A. and Duldig, M., Adv. Geosci., 112, 2007. 